\title{
ESCRITOS CIRCUNSTANCIALES, PENSAMIENTO SITUADO
}

SERCIO ROMERO Albricias ediciones. Colección tierra del Elqui. La Serena, 2014. 172 Pácinas.

ISBN: 978-956-9452-00-0

El libro del profesor Sergio Romero fue Epresentado el día 5 de junio de 2014 en la Universidad Católica del Norte (sede Coquimbo) a pesar de haber sido impreso en febrero de este mismo año. Lo sucedido se debió a que en el mes de marzo estaba programado su lanzamiento, pero producto del terremoto del norte tuvo que aplazarse, generándose así un Coloquio denominado Filosofía, Educación y Sociedad: "Situación y

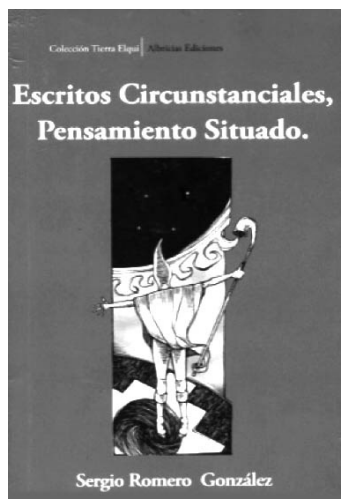
circunstancia". En aquel expusieron varios académicos desde distintas vertientes filosóficas a propósito del libro presentado, entre ellos Sergio Rojas, con la ponencia denominada "Localidad y mundialización: El relato Latinoamericano", y que además es quien presenta en el prólogo el libro del profesor Romero.

En esta reseña se presentan algunas indicaciones con respecto al libro de Romero, desde la perspectiva escritural y como donación de sentido, y por último, la figura del promesante.

Al leer el texto del profesor Romero, lo primero que llama la atención es el nombre del libro: "Escritos circunstanciales. Pensamiento situado". Este reparo radica en que el significado no pareciera interpelar

1 El profesor Sergio Romero ejerce en la Universidad Católica del Norte (sede Coquimbo) en las carreras Pedagogía en Filosofía y Religión y Licenciatura en Ciencias Religiosas. 
al lector desde aquellos títulos filosóficos tradicionales que en gran medida pretenden desarrollar alguna idea trascendental o proyecto filosófico que cruce las "fronteras" culturales para posicionarse en otra parte del mundo, es decir, pareciera que en su nombre no tiene pretensiones de un proyecto filosófico. Se entiende por ende, y el mismo autor lo explica, que se fue articulando por la misma práctica filosófica reflexiva, que se experiencia en él, donde camina la reflexión de manera lenta..., silenciosa... a mano..., y escrita en distintos momentos con diferentes finalidades prácticas ${ }^{2}$, y que a pesar de los diferentes tiempos involucrados, contienen una ilación (pareciera invisible, aquella que recoge una vida y pulsa por salir), cuestión que se vuelve evidente al dar a conocer al lector la reiteración constante de algunos temas trabajados.

La insistencia de los temas (que por cierto no son tan reiterativos) explicita un modo de hacer filosofía desde su propia identidad. Un acto de sinceridad intelectual, que demuestra por una parte, la riqueza del pensamiento en silencio y el ordenamiento que desde la teoría permite mirar su propia realidad latinoamericana (desde la caleta de Coquimbo) construida por autores leídos, comentados -en diálogo-, acompañados o dejados. Desde aquí aparecen los "fantasmas intelectuales" que ayudan a configurar el diagnóstico y la propuesta del texto.

Lo segundo que llama la atención desde el título es cómo se ordena el texto. En una primera mirada, desde la posición de lector, al comparar cómo habitualmente se ordena un libro con respecto a la tendencia tradicional de escritura filosófica, se podría decir que concuerda. Ahora bien, alguien se podrá preguntar cómo es "aquella tendencia de escritura filosófica" sabiendo de antemano que existen diferentes formas, por ejemplo un diálogo o una obra de teatro. Se podría plantear que habitualmente se elabora desde un movimiento deductivo, es decir, por medio de una confrontación general de autores que

2 Por ejemplo, el capítulo VI, se articula desde una presentación denominada Cuerpo, tortura y fiesta para la experiencia de latinoamericanismo, en el II Congreso Internacional de Estudios Latinoamericanos del año 1999 en la ciudad de La Serena, Chile. 
presentan obviamente un problema, decantan en algunas ideas que configuran su auscultación, luego se toma posición con respecto a lo que se discute y por último se hace una propuesta, indicaciones, o quizás nuevas preguntas.

Bajo el movimiento anterior pareciera estar articulado el texto, lo cual desdice al propio título, creando una ilusión de que por más que sea una propuesta innovadora y provocante, se constituye como si fuera lo mismo. Quizás sea problema de forma u organización de los mismos artículos, aunque se aprecia ya desde una segunda o tercera lectura, que el problema que el autor quiere abordar es sobre el problema de la identidad latinoamericana, por lo mismo, circunstancial y situado es ya un lugar pertinente y novedoso de reflexión. Escribir de manera circunstancial es en definitiva aquello que nos pasa como experiencia latinoamericana, y en aquellos contextos y momentos, se dan las situaciones. En la figura del "promesante" que propone el autor, nos permite adentrarnos a este tipo de reflexión.

Una de las críticas de la Gramaticología Derridiana sobre el efecto de la escritura, es el desplegar sentido a través del tiempo. En este proceso, lo que se envían son ideas, definiciones, resignificaciones... en definitiva, metaforizaciones que permiten que la escritura se sobreescriba. Lo que se mantendría es la "usura de la filosofía" (a propósito de la producción hermenéutica). Al remitir a esta idea, lo que se quiere dejar en evidencia es que el sentido que se traspasa es aquello que nuevamente aparece como problemático y que su respuesta anterior vuelve a tener sentido en otro momento o contexto histórico, pero con puntos de vista diferentes. Desde aquí se puede plantear: ¿por qué es relevante la discusión del autor sobre la filosofía latinoamericana siendo que aquella discusión se desarrolló desde mediados del siglo XX? ¿Qué novedad habría en aquella reflexión si ya es una discusión antigua? Por otra parte, si una pregunta vuelve pero de otro modo, ¿cómo vuelve la pregunta y por qué vuelve?

Habría que decir, la preocupación por el ser latinoamericano (o por lo propio del sujeto latinoamericano) hoy vuelve también por algunas preocupaciones institucionales. Antiguamente como resistencia a un 
proceso de implantación de hegemonía cultural, hoy institucionalizada otorgando valor fundamentalmente al problema de las culturas, por ejemplo la creación de programas de Doctorado, seminarios, coloquios, etc... que abordan el problema de lo intercultural. Una de las diferencias de dos momentos históricos como lo fueron en el año 70 y en el 2014, son los dos contextos, donde entremedio se implementó un sistema de libre mercado bajo la dictadura militar, desdibujando el panorama social y político. Por esto, hoy siguen apareciendo como problemáticas de corte social, la desigualdad social, los problemas de género y, el incipiente pero cada vez más relevante tema de la inmigración.

Entonces la pregunta vuelve, pero de otro modo... Quizás se podría cuestionar por qué vuelve, para quién vuelve y cómo vuelve. En definitiva, la preocupación del profesor Romero traspasó esos años donde en gran parte de América Latina no se podía pensar, ni menos hablar. Ahora la reflexión se legitima de manera institucionalizada, y todavía no vemos los alcances de esta nueva vuelta.

Los temas que están orientando la reflexión en el texto y que permiten al académico obtener algunas conclusiones son por una parte, la constatación de la caída de los metarrelatos (J.F. Lyotard), el pensamiento periférico (o del margen) y del ser latinoamericano (A. A. Roig), entre otros. Estos autores permiten plantear la constatación de que hoy es posible pensar América Latina debido a que la modernidad y el capitalismo están en una fase de agotamiento, a pesar de seguir posicionándose, lo harían ya como una sombra. Esta permitiría volver hacia lo propio, es decir a su propuesta antropológica.

Por otra parte, se aprecia en el texto una de las ideas más provocadoras sobre el ser latinoamericano. La figura del "promesante", la cual es su propuesta experimental para provocar en otro reflexiones sobre las diversas circunstancias latinoamericanas (la figura es evocadora). El promesante es una figura que se desprende de la experiencia frente a la Virgen de Andacollo, es aquel que se deja llevar por el sentido que otorga la deidad a través del baile y por lo tanto, por medio del movimiento corporal. Esta experiencia, permite "ordenar el caos inicial manteniéndose un compás cósmico, lo que no quiere decir, que el 
caos ya no existe sino más bien la música y el baile construyen en él una coreografía" (p. 135).

La importancia de la reflexión de Sergio Romero radica primeramente en atreverse a pensar. Y qué significa pensar en el texto, pareciera que es imperioso de su parte reconocer la experimentación como una propuesta de retorno (el promesante en diálogo con el todo) en eso que vuelve (el mito). Esta forma de pensar, según el autor, tendría una mayor pertinencia cuando se habla de América Latina y específicamente en Chile.

Pablo Solórzano Marchant.

Profesor de Filosofía UCSH. 